\title{
AS MINAS E OS GERAIS: BREVE ENSAIO SOBRE DESENVOLVIMENTO E SUSTENTABILIDADE A PARTIR DA GEOGRAFIA DO NORTE DE MINAS
}

\author{
THE MINAS AND THE GERAIS: A BRIEF ESSAY ON DEVELOPMENT AND \\ SUSTAINABILITY FROM THE GEOGRAPHY OF THE NORTH OF MINAS
}

\section{LAS MINAS Y LOS GERAIS: BREVE ENSAYO SOBRE DESARROLLO Y SOSTENIBILIDAD DESDE LA GEOGRAFÍA DEL NORTE DE MINAS}

\author{
Carlos Walter Porto-Gonçalves ${ }^{1}$ https://orcid.org/0000-0001-5578-3231
}

\footnotetext{
${ }^{1}$ Doutor em Geografia-UFRJ e Pós-Doutor pela UFSC. Professor Titular do Departamento de Geografia da Universidade Federal Fluminense. E-mail: cwpg@uol.com.br
}

\section{RESUMO}

A presente edição ${ }^{2}$, revista e atualizada, reedita o ensaio elaborado no final da década de 1990 a partir de trabalhos de campo e atividades de extensão e pesquisa em diálogo com camponeses e camponesas do Norte de Minas a partir da avaliação do trablaho realizado na região pelo Centro de Agricultura Alternativa - CAA. As primeiras versões foram apresentadas e debatidas em Porto-Gonçalves (1997 e 2000). Assim, apresenta-se uma análise sobre o Norte de Minas Gerais a partir do des-envolvimento regional.

Palavras-chave: Norte de Minas. Campesinato. Povos e Populações Tradicionais. Desenvolvimento Regional. Sociobiodiversidade.

\begin{abstract}
This revised and updated edition reissues the essay prepared in the late 1990s based on fieldwork, extension, and research activities in dialogue with peasants in the north of Minas Gerais, based on the work carried out in the region by the Alternative Agriculture Center - CAA. The first versions were presented and discussed in Porto-Gonçalves (1997 and 2000). Thus, an analysis of the North of Minas Gerais is presented based on regional development.
\end{abstract}

Keywords: North of Minas. Peasantry. Traditional Peoples and Populations. Regional development. Sociobiodiversity.

\footnotetext{
${ }^{2}$ Essa edição rigorosamente se manteve fiel à edição original, afora a revisão de pequenos erros de digitação. Somente acrescentamos no final algumas referências bibliográficas recentes que permitem uma comprensão mais qualificada da região hoje. Para isso agradeço a contribuição dos editores da Revista Verde Grande - Geografia e Interdisciplinaridade. Nota do autor.
} 


\section{RESUMEN}

La presente edición, revisada y actualizada, reedita el ensayo elaborado a finales de la década de 1990 sobre a partir del trabajo de campo y las actividades de extensión e investigación en diálogo con campesinos y campesinas del Norte de Minas Gerais, a partir de la evaluación del trabajo realizado en la región por el Centro de Agricultura Alternativa - CAA. Las primeras versiones fueron presentadas y discutidas en Porto-Gonçalves (1997 y 2000). Así, se presenta un análisis sobre el Norte de Minas Gerais basado en el desarrollo regional.

Palabras clave: Norte de Minas. Campesinado. Pueblos y poblaciones tradicionales. Desarrollo regional. Sociobiodiversidad.

\section{I - A FORMAÇÃO DE UMA REGIÃO A PARTIR DE UM MUNDO QUE COMEÇA (COLONIALISTICAMENTE) A SER MUNDO ${ }^{3}$}

1 - A apropriação/conquista da região do Norte de Minas deve ser entendida como parte do processo de expansão do colonialismo mercantil português. Destaque-se que a Coroa portuguesa tomou cuidados tentando evitar que a ocupação/povoamento ganhasse o interior da colônia-Brasil e, assim, aumentasse as distâncias do litoral dificultando o controle político e administrativo por parte da metrópole.

Reconhecemos aqui um "silêncio", de graves consequiências histórico-políticas, que é o de considerar a nossa história a partir da colonização portuguesa, ignorando-se toda a tradição das matrizes de racionalidade de outras populações que aqui existiram previamente à chegada dos invasores (que se autodenominavam colonizadores). Para uma análise que se pretende incorporando a dimensão ambiental, esse "silêncio" tem graves conseqüências, pois deixa de lado todo conhecimento tecido em íntima relação com os ecossistemas pelos indígenas, em parte guardado no saber da medicina, da arquitetura e da culinária populares ignorando, assim, sua dívida para com os índios.

Tal silêncio é, ainda, responsável por um dos grandes mitos de invenção portuguesa, que é o de "vazio demográfico" da colônia. Este mito é de uma tal inversão da realidade que foi capaz de ignorar que a população da colônia era, no mínimo, oito vezes maior que a da metrópole. No entanto, se era um vazio demográfico estava, de antemão, justificada a ocupação. Como, na verdade, a colônia já estava ocupada, todo o processo de colonização foi,

\footnotetext{
${ }^{3}$ Dedicado a Carlos Dayrell, Claudia Luz, João d'Angellis, Geraldo, Álvaro, Mazzan, meus amigos, e amiga, todos técnicos do Centro de Agricultura Alternativa e que acreditam na importância do que sabem, e que sabem que o que sabem não é tudo. Ao Oscarino da Lagoa, ao Braulino das Abóboras, à Rosário da Catarina, à Nilza da Catarina, à D. Ana da Lagoa, à D. Nem de Laranjeiras, ao José Lelis de Porteirinha, à D. Josefa de Taboquinhas que conhecem os mistérios do cerrado e da caatinga encerrados nos procedimentos do saber-fazer. Ao Eric Sabourin, como eu. Deste que sabe que o que sabe é dizer o que eles sabem, e que não sabe fazer o que eles fazem. Assim, dedico. Tendo dito. Faço o meu saber.
} 
ao mesmo tempo, de extinção e não só de ecossistemas, mas de populações/culturas inteiras. Matar e Desmatar são, assim, dois verbos, duas práticas, indissociáveis na história/geografia do Brasil. A Amazônia e o Cerrado, parte do qual está no Norte de Minas, e suas respectivas populações foram, recentemente, as últimas vítimas da ocupação deste "vazio demográfico".

2- A região, por suas características geoecológicas, sobretudo aquelas que derivam da semi-aridês-caatinga e do clima tropical-cerrado, aliada a um relevo onde os contrafortes ocidentais da Chapada Diamantina-Serra do Espinhaço que, com suas formas acidentadas, quebram a monotonia das chapadas, não se apresentava à feição para o cultivo da cana de açúcar, produto que plasmou a paisagem do Nordeste Oriental Úmido.

No Nordeste, de onde partiria o horizonte do colonizador que, por desconhecer o Sertão, mais seco, chamou àquela região de agreste. Na verdade, era agreste porque não era fértil e ser fértil, ao olhar do colonizador, era ser boa para o plantio de cana. Não era o conhecimento da realidade que levava à denominação de uma determinada região, mas sim a adequação ou não da região à vontade do rei, no caso a expansão da cana de açúcar. Assim, não é natural que chamemos o Agreste de Agreste, assim como não é natural que se diga que o fertilíssimo solo de massapé da Zona da Mata Nordestina seja naturalmente vocacionado para o plantio de cana de açúcar, até porque, sendo fértil, muito bem pode produzir uma gama mais elástica de riqueza de interesse popular, como alimentos, por exemplo. Dizer que o massapé é naturalmente bom para plantar cana é tornar natural a vontade do Senhor de Engenho de plantar cana e importar todos os gêneros de que se necessita para sobreviver e, até, de proibir que se plantasse o que não fosse cana. A febre de plantar cana chegou a um tal nível de irresponsabilidade que, quando da invasão holandesa no Nordeste, e uma outra lógica que não a do Senhor de Engenho se fez presente, os novos invasores impuseram um decreto de obrigatoriedade de plantação de mandioca para garantir a alimentação dos escravos.

3- A região do Norte de Minas será geográfica e historicamente conformada por esse contexto histórico (colonial)-geográfico (ecológico): (1) os objetivos de cultivo de cana, inicialmente; (2) as condições de distância geográfica do litoral, isto é, das feitorias e dos portos; (3) as condições ecológicas semi-áridas em transição para um clima tropical de cerrado, agreste para o cultivo de cana e; (4) o sentido Norte-Sul dos Complexo EspinhaçoDiamantina que condicionou a drenagem, sobretudo do Rio São Francisco e, assim, as condições de acesso à região a partir da colonização do Nordeste brasileiro.

4- Tanto foi assim que o Norte de Minas foi parte da capitania da Bahia, pelo que tinha situado a leste do São Francisco, e parte da capitania de Pernambuco, pelo que tinha situado a 
oeste do Velho Chico. Há, portanto, raízes históricas para que o Norte de Minas esteja hoje ligada à SUDENE e não exclusivamente por causa da semi-aridês.

\section{...E A REGIÃO CONFORMA SUA IDENTIDADE}

5- A região do Sertão do São Francisco, da qual o Norte de Minas faz parte, plasmou sua organização socio-espacial em relação com, pelo menos, dois grandes "ciclos" da história econômica luso-brasileira: a cana de açúcar e o ouro. Da relação com o Nordeste açucareiro e com a região do ouro-diamante (Vila Rica-Ouro Preto, Sabará, Mariana, etc.) que, pontualmente, atingiu diretamente a região do Norte de Minas (Grão Mogol, Salinas, além de Diamantina, já no Vale do Jequitinhonha), viria a região formar suas características básicas.

Destaque-se o fato de que a região não podia esperar que viesse, seja da região da cana, seja da do ouro, os produtos que a pudesse abastecer. Aquelas outras regiões podiam importar os víveres de primeira necessidade, o que sustentava o próprio regime do exclusivo colonial que, inclusive, proibia a produção do que quer que fosse que pudesse ensejar alguma possibilidade de auto-suficiência. Desta forma o Grande Sertão não só viveu de fornecer gado e derivados da pecuária para a região da cana e do ouro cada um, a sua vez, "ciclo" hegemônico da colônia.

A região teve que forjar suas próprias condições de auto-sustentabilidade. E aqui talvez resida uma das características mais originais desta região: a de não ter a sua dinâmica diretamente determinada por uma racionalidade econômica mercantil de algum produto em que a metrópole estabelecesse o régio controle direto.

Embora a pecuária se constituísse na atividade principal dos grandes latifundiários, que estavam entre os maiores entre os grandes, a região teve uma riqueza enorme criada pelas famílias de agricultores pobres, pobres num contexto onde o rico é ser dono de imensas extensões territoriais. No entanto, é a riqueza da cultura desses Caatingueiros, desses Geraizeiros, desses Vazanteiros, cultura essa expressa num diversificado regime alimentar, que vai fazer com que Josué de Castro, famoso geógrafo e médico pernambucano, afirmasse que a fome no Sertão, ao contrário do Nordeste açucareiro ou do cacau, não era endêmica, mas epidêmica, restrita aos momentos de seca.

6- A riqueza do regime alimentar da região é, ao mesmo tempo, a expressão maior do cruzamento da questão social com a questão ecológica, posto que o alimento é a energia que o corpo humano necessita, como qualquer outro ser vivo. $\mathrm{O}$ regime alimentar, tecido ao longo dos séculos pelos Geraizeiros, pelos Caatingeiros, pelos Vazanteiros, é o resultado do modo como essas populações se apropriaram das diferentes condições naturais que a região oferecia, 
seus brejos/várzeas, suas encostas, suas chapadas, seus cerrados, suas matas secas, suas caatingas ensejando seus sistemas agrícolas.

Deste modo, mais do que a pecuária, atividade que a região, sem dúvida, tem uma tradição, há uma agri-cultura, há o requeijão, o queijo de Minas, o cuscuz, a rapadura, o licor de pequi, a cachaça, o charque, a farinha, o bolo de milho, além dos remédios... É, sem dúvida, um regime alimentar dos mais genuínos, que se convencionou chamar a Cozinha Mineira que, por sua vez, foi desenvolvido nas brechas, nos interstícios da cultura dominante que era menos agro e mais pecuária.

Compreende-se que tenha sido o gado que fez a fama, até porque era ele que dava conteúdo oficial, régio, à ocupação/conquista desses sertões. Era ele a "moeda de troca" com as demais províncias da colônia. No entanto, será pelas mãos desses que lavram a terra que todo um conhecimento será tecido em íntima relação com os diferentes nichos ecológicos, onde a água sempre foi objeto de uma atenção especial, até porque se foi um fator limitante à expansão da cana, era necessário que bem se soubesse apanhá-la (o sem-número de localidades, distritos ou municípios cujos nomes remetem a água é a expressão da sua importância: Córregos, Riachão, Lagoa, Riacho dos Machados, Varzelândia...).

Assim, o sabor -saveur- da Cozinha Mineira tem como suporte um saber -savoir- que, além disso, será capaz de nos legar um Norte de Minas basicamente auto-suficiente em alimentos até cerca de 25 anos atrás.

Há, assim, um gênero de vida (Vidal de la Blache) que tem no regime alimentar seu nexo de ligação da relação homem-natureza, que perdurou até muito recentemente, e de onde necessariamente ter-se-á que partir se se quiser partir de algo que tenha enraizamento culturalecológico. Não nos esqueçamos que, como nos ensinara Levi Strauss, a culinária transforma o cru no cozido e, como tal, a natureza em cultura.

Há, assim, uma singularidade histórico-cultural a partir do que haverá que se estabelecer um diálogo com essas outras matrizes de racionalidade. Assim, se sempre foi destacada a hegemonia do latifúndio pecuarista, é preciso se registrar, pela importância que teve na configuração do perfil socio-geográfico-cultural da região, a produção familiar desses Geraizeiros, desses Caatingueiros, desses Vazanteiros...

7- A apropriação da terra na região do Norte de Minas teve as marcas do latifúndio do período colonial. O vale do São Francisco foi palco dos maiores latifúndios da história, como os da família D`Ávila. No entanto, se houve uma apropriação desigual que se legitimou juridicamente houve, também, enormes extensões de terras que não foram apropriadas privadamente e que ensejaram a possibilidade de um sistema de uso da terra que está 
subjacente à diversidade cultural da região, inclusive, ao seu regime alimentar. E mais: contribuiu de tal forma para plasmar a identidade política e cultural de Minas que lhe emprestou seu caráter de Gerais.

Havia, além das minas de ouro que eram da administração geral, da metrópole portuguesa, os campos gerais.

Os Campos Gerais, denominação que aparece no Paraná, Santa Catarina, Minas Gerais, Maranhão, Roraima etc. não têm uma especificidade ecológica. Procure-se nos livros de Biogeografia e de Ecologia a caracterização desse possível bioma e nada teremos. É que Campos Gerais indicam um modo de uso, um modo de apropriação comum, geral das terras. Indica que eles não são particulares, privados. São Gerais, são comuns.

Deste modo, em vastas porções do território brasileiro temos, para além do latifúndio, as terras comunais, que eram as terras públicas...gerais. É ali que se vai pegar a lenha. É ali que se vai pegar a madeira para fazer um utensílio doméstico. É ali que se vai pegar uma erva para fazer um remédio. É ali que se deixa alguma cabeça de gado pastando à larga, enquanto se planta no brejo, na várzea, ou na encosta.

Enquanto houve esses Gerais, puderam se reproduzir essas culturas, esses modos de produção, esses modos de vida, usando, inclusive, a rotação de terras... Podia-se, até mesmo, "voltar depois de 10 anos à terra de onde se partiu", conforme me disse um Geraizeiro. E isso é uma referência do que ocorria até cerca de 30 anos atrás. As terras hoje já não são Gerais...embora estejam expirando [nos anos 1990) o prazo de 20 anos de muitas das concessões feitas pelo regime militar dessas terras gerais para empresas particulares nos anos 1970. Eis uma questão que deve voltar ao debate sobre o destino das terras no Brasil e em Minas, em particular.

8- Numa região tão distante e onde o interesse da Coroa portuguesa era sobretudo de controle do território, economicamente secundário, em relação à cana ou ao ouro, o poder local dos latifundiários, esse sim, era, paradoxalmente, maior. Sob esse "mandonismo" dos grandes proprietários forjou-se, assim, uma sabedoria no "trabalhar em silêncio", pois não há, propriamente, uma esfera pública onde se possa falar abertamente. A lógica do favor se sobrepõe à lógica do direito. O latifundiário não tem só poder econômico, mas também o de fazer justiça na prática, até pelo isolamento. O Coronelismo sentará profundas raízes na região do que, talvez, a inserção do Norte de Minas no Polígono das Secas e, a partir daí sua vinculação à SUDENE, com todo o seu séquito de suporte do poder público a esses "Coronéis", é uma expressão. 


\section{O DES-ENVOLVIMENTO DA REGIÃO: OS 'DE FORA' E OS 'DE DENTRO', OS 'DE CIMA' E OS 'DE BAIXO'}

9- Quando, a partir dos anos cinquenta/sessenta, o modelo desenvolvimentista passa a comandar o país, inclusive desencadeada por um presidente da República (JK) nascido no vale do Jequitinhonha, a região passará por uma verdadeira revolução na sua organização socio-espacial.

Os latifúndios, considerados improdutivos, tal como prescreve o Estatuto da Terra de 1964, deveriam se modernizar, ou seja, se transformar em Empresas Rurais, não importando que sobre a mesma estrutura de propriedade concentrada da terra. Os incentivos governamentais sob a forma de isenção fiscal ou de concessão de terras públicas, gerais, foram colocados à disposição de empresários que abraçaram essa ideologia modernizadora. Assim, se a riqueza e o poder já eram concentrados em poucas mãos, necessariamente mais concentrados se tornaram com a modernização, exatamente por se aumentar a produtividade.

Os Gerais, ou seja, as terras públicas das chapadas dos sertões do norte de Minas, se tornaram particulares, seja pelas mãos do Estado, através de contratos de concessão de uso para as grandes plantações de eucaliptos, seja pela apropriação à mão grande, na ponta do fuzil. Tudo isso articulado ao polo siderúrgico do Quadrilátero Ferrífero, fornecendo carvão de ótima qualidade, vegetal, para queimar nos alto-fornos e/ou nas indústrias de ferro-ligas de Sete Lagoas, Capitão Eneas, Várzea da Palma, Pirapora, Ipatinga, Bocaiúva, Betim ,...

Temos, assim, a modernização conservadora a la Norte de Minas. Com ela o pequi vira carvão, ele que era, segundo a tradição indígena, o alimento que surgiu dos céus para propiciar a vida no cerrado.

10- De um lado o desemprego, fruto da desestruturação do sistema agrário que envolvia os produtores familiares e, de outro, a diminuição da disponibilidade da água, não devido a alguma diminuição dos índices pluviométricos, que se mantém nos mesmos níveis nos últimos vinte anos, mas à sua apropriação desigual, tem ensejado uma política de grandes projetos de irrigação que, longe de resolver o problema, torna-se o pivô de seu agravamento, ironicamente com seus pivôs centrais.

A queima do cerrado e os próprios eucaliptais, a despeito de se dizer que não há provas científicas, leva a que as famílias de agricultores sintam a falta das minas ... de água. "A zoeira da água atrapalhava até nóis dormir. Hoje tá tudo seco", diz D. Josefa, da Comunidade Taboquinhas, no município de Mirabela. Para essas famílias não há mais Gerais, que foram cercados, privatizados, nem, tampouco, há minas ... de água 
Aqui vivemos, entre duas verdades, um enigma a decifrar: a média pluviométrica se mantém equivalentes nas duas últimas décadas, nos informam os dados técnicos oficiais; de outro lado, as famílias de produtores rurais, invariavelmente, acusam a escassez de água.

Tudo indica que a mudança no sistema de uso da terra, seja através das monoculturas de eucaliptos; seja do desmatamento-queimada do cerrado para fazer carvão; seja das apropriações da água pelos grandes projetos de irrigação; seja com os pivôs centrais, se não alterou o índice médio de chuvas, sem dúvida, alterou o regime hídrico regional.

A captação de água tem se tornado alvo de interessantes debates e lutas, onde lógicas (de classes sociais) diferenciadas se confrontam, como na que se trava no Riachão, entre os grandes captadores de água, com sua proposta de uma grande barragem e, de outro, os produtores familiares, propugnando por uma série de mini-barragens nos subafluentes do Riachão, para que a água seja captada por mais e outras famílias.

11- Esse processo de des-envolvimento regional introduziu, além da monoprodução de eucalipto, a queima do cerrado para fazer carvão, os projetos de irrigação, a subordinação do produtor familiar a uma monoprodução, seja de algodão, como foi o caso da região de Porteirinha e Riacho dos Machados, seja de uma fruticultura irrigada, ambas vinculadas a empresas que industrializam essas matérias primas. O mesmo vem sucedendo com o leite e suas "cooperativas". Mais do que produtos determinados -algodão-frutas-leite é preciso que se observe que o que estava sendo gestado era um sistema que subordinava a produção familiar, através de um pacote técnico, a cooperativas empresariais que, sabemos, têm mais de empresariais que de cooperativas, e através delas às indústrias de beneficiamente dessas matérias primas atraídas para a região, com um farto sistema de isenções e incentivos fiscais.

É a dependência do produtor familiar às sementes melhoradas, ao gado cientificamente produzido, tudo isso através de empresas que vêm "ajudar" a fazer projetos para o pequeno produtor.

A monoprodução foi imposta como condição para que se obtivesse apoio técnico e financiamento bancário, conforme o depoimento de vários agricultores. Assim, não se partiu das matrizes de racionalidade dos Geraizeiros, dos Caatingueiros ou dos Vazanteiros, que nunca foram monoprodutoras e que, como vimos, garantiam não só o auto-abastecimento da região, como, também, dos tropeiros.

O pequi que virou carvão é, assim, a mudança radical de uma matriz de racionalidade a outra; de uma que produzia riqueza, através de um modo de vida que transformava o cru em cozido, isto é, a natureza local/regional em cultura: o pequi em refeição, em licor; para uma 
outra racionalidade preocupada com a expressão monetária da riqueza, o dinheiro, que não é a riqueza mesma.

Hoje percebe-se, tal como Rei Midas da mitologia grega, que não se pode matar a sede com dinheiro. A diferença entre riqueza (a água) e a expressão abstrata (o dinheiro) se mostra concretamente na condição de calamidade pública. Tem-se carvão no lugar do pequi, mas o carvão só vale como valor a ser trocado, por dinheiro, e passa-se a ter dinheiro para importar o alimento que antes se tinha. Aliás, importa-se um alimento standartizado/padronizado, igual por todo lado.

Desse modo a diversidade de matrizes de racionalidade da região -a Caatingueira, a Geraizeira e a Vazanteira-, com todo o saber que produziram sobre os ecossistemas e todos os sabores a essas matrizes associados, se vêm hoje ameaçadas de extinção/destruição, ou se vejam recuperadas, de modo descontextualizado, através de um neonaturismo e um neoarcadismo (conforme Edgar Morin) nos restaurantes sofisticados dos grandes centros ou das cidades do circuito turístico. Assim, só para os sofisticados é possível comer feijão tropeiro, ou um bom queijo de Minas, ou um requeijão, em alguma loja sofisticada de algum bairro/cidade sofisticado/a.

Nessa perspectiva de que só poucos gozem dessa riqueza, necessariamente as matrizes de racionalidade responsáveis por sua produção serão marginais na paisagem, deixarão de imprimir suas marcas, suas grafias na terra, de fazer suas geografias. Estarão, rigorosamente, fora do mapa.

12- Assim, a região que tinha seu próprio envolvimento foi des-envolvida. A sociedade local/regional que, à sua moda, com suas próprias contradições, determinava o que ia ser feito dos seus, mesmo que desigualmente repartidos, recursos naturais assim como de outras riquezas, vê des-locado, ou seja, vê tirado (dos do) do local, (dos da) da região, o poder de determinar os seus destinos.

Há uma determinação superior, de um Brasil-Grande, que vai levar/trazer o desenvolvimento o que, rigorosamente falando, significa des-envolvimento. O Norte de Minas tinha um envolvimento próprio, com contradições próprias e, enquanto uma região, conformava uma relativa autonomia quanto à sua dinâmica de uso dos recursos naturais, o que ensejou culturas próprias, matrizes de racionalidade diferenciadas, materializadas e corporificadas no Caatingueiro, no Geraizeiro, no Vazanteiro... Há que se refletir sobre a possibilidade de que se tenha uma perspectiva de sustentabilidade, como hoje se coloca, a partir de um modelo de desenvolvimento que tende, cada vez mais, a tirar dos lugares, das populações dos lugares o poder, isto é, a possibilidade de traçar os seus destinos... 
O processo que vem se dando, sobretudo a partir da década de 70 é, nesse sentido, a quebra desse envolvimento, o des-envolvimento, o que significa que a autonomia ficou cada vez mais relativa, cada vez menor a capacidade/possibilidade de determinar os seus destinos. Nesse sentido des-envolver foi, também, des-locar, ou seja, tirar dos locais, dos do local, o poder.

No entanto, não houve nenhuma invasão à região, como poderia parecer à primeira vista. O que mudou, a partir dos anos setenta, foi o modo de inserção da região à divisão nacional/internacional do trabalho, com as marcas das nossas tradições culturais e políticas: as transições "por cima", onde os "de baixo" não são vistos como portadores de direitos e, agora, com a modernização, tampouco, de favores.

Não se compreenderá essa transição, com transformações tão radicais na organização socio-espacial da região, se ficarmos prisioneiros de uma lógica econômica. Não resta a menor dúvida que uma das marcas dessa transformação foi uma dissociação mais radical entre o homem e natureza; a apropriação das terras e das águas, dos cerrados, através de sua mercantilização, assim como as próprias famílias se viram expulsas e concitadas a migrar e a se assalariar, muitos lançados ao subemprego e à marginalização social, como a cidade mais importante da região, Montes Claros, registra através do aumento significativo de subhabitações que marcam sua paisagem.

Não resta dúvida que é a lógica do dinheiro, ou como se costuma dizer, a lógica do mercado, que passou a comandar a organização do espaço regional. Por isso queimou-se pequi para fazer o carvão, acabou-se com as terras comunais, na região Gerais, para plantar eucalipto, introduziu-se a monocultura do algodão onde havia policultura, passou-se a irrigar quando antes a água existia com mais fartura.

Não há como deixar de ver aqui uma das marcas da tradição coronelística, tão bem expressa no depoimento de um líder político do Sertão pernambucano, citado por Raimundo Faoro, e que diz "Mudou o governo, mas eu não mudo. Estou com o governo". Esse adesismo governamental, como nos ensina Vitor Nunes Leal, é uma das expressões mais características do fenômeno coronelístico que, entre outras coisas, vê que "em política a única vergonha é perder". Temos, assim, modernização conservadora a la norte de Minas.

Junto com esse processo temos a desqualificação cultural do homem local/regional. Seu tempo, seu ritmo é considerado lento, numa nova versão das velhas ideologias colonialistas de que são indolentes e preguiçosos. Seu conhecimento é ignorância. Ou, como a própria palavra sugere, des-envolvimento vem de fora. 
Uma das marcas do espírito dessa nova época é o da velocidade das transformações. Tudo passa a correr mais rápido. Assim, os outros tempos são a esse tempo hegemônico referenciados. Na verdade, sempre em defasagem, lentos, face a esse tempo dominante. É a lógica do dinheiro invadindo corações e mentes, a lógica do "time is money".

A partir de então o moderno na região é o gaúcho, descendente de alemães ou de italianos ou, ainda, o japonês que vem fazer milagre. O moderno é a irrigação. O moderno é a monocultura. O moderno é o reflorestamento, eufemismo encontrado para a monocultura do eucalipto. O moderno é o carvão. O Geraizeiro, o Caatingueiro, o Vazanteiro são vistos como sinônimos de atrasado, de atraso a ser superado. Há assim um relógio a que os demais têm que acertar o passo.

Eram, além de tudo, policultores. Há, assim, um verdadeiro confronto, onde os "de fora" e "de cima", se aliam com os "de cima" da própria região e, portanto, "de dentro", para promover um progresso verdadeiramente contra "os de baixo".

13- Contra a dominação político-cultural - o mandonismo, o clientelismo, o coronelismo - a tradição regional registra o messianismo e o banditismo. O bandido-herói é, ao mesmo tempo, aquela figura ambígua que faz-justiça-por-e-para-si-mesmo-sem-asinstituições e só nisso difere daqueles que fazem justiça-por-e-para--si-mesmo-e-com-asinstituições. O bandido-herói, de que um pouco mais ao norte Lampião foi o melhor exemplo, e que teve seus exemplares na história da nossa região e está na memória popular, ao mesmo tempo circula nos interstícios das contradições entre famílias poderosas (inclusive dando proteção e recebendo abrigo em suas fazendas).

14- O processo que se vive atualmente restringe a possibilidade de se ter um pedaço de terra nos Gerais, ou mesmo de se morar de favor no interior do grande latifúndio. Com a privatização dos Gerais, já não é mais possível se ir pegar madeira, ou ervas e remédios, ou deixar pastar à solta o gado. Com o carvão, os eucaliptos e os projetos de irrigação, as águas já não minam nas minas do Norte de Minas. Os brejos começam a secar e, com isso, a cultura do feijão, do milho, da cana, do arroz, e outras do fundo dos vales, já não permitem fazer valer aquelas velhas matrizes de racionalidade, que ensejaram aquele regime alimentar rico e variado a que nos aludimos.

Já não é possível sequer viver de favor num latifúndio modernizado. A Empresa Rural, nome desses latifúndios modernizados, não é uma instituição dada a essas veleidades tradicionais. O favor é, agora, sobretudo, ao político que pode arrumar um emprego, um transporte, se alguém está doente, e se é um cabo eleitoral. Votar nele é um agradecimento 
sincero de quem vota, mantendo no poder o político que vive da reprodução da sua precisão e daquela sinceridade.

As cidades crescem e o empreguismo é um capital nas mãos desses políticos literalmente conservadores. Se antes se morava de favor, ou se dependia dos favores do latifúndio, agora se faz o favor de colocar uma bica d'água, iluminar um beco ou qualquer outro "melhoramento", nas muitas favelas que se multiplicam, também, pelo interior. O populismo se transforma na versão urbana do velho "coronelismo". Em comum têm a visão de não ver os de baixo como alguém que seja portador de direitos, um cidadão.

15- Diante desse quadro regional/nacional emerge uma resistência de novo tipo, até então ausente na região, e em grande parte do interior do país. Sem dúvida uma instituição nacional, enraizada local/regionalmente, será a responsável por introduzir um novo vetor de resistência: a Igreja, sobretudo aqueles setores da Igreja Católica ligados à Teologia da Libertação. Registre-se, por sua importância na compreensão dos processos socio-políticos envolvidos, que há um vetor que emana de uma escala nacional e, até mesmo internacional, que é a Teologia da Libertação. Não fôra essa dimensão e o enraizamento local/regional secular da Igreja na região continuaria intimamente vinculado às estruturas de dominação tradicionais. Um exemplo: a maior parte das capelas e mesmo de Igrejas, para não falar dos cemitérios onde estão enterrados os ancestrais, estão localizados nas fazendas ou foram construídos por fazendeiros. É ali que se confessa...e não raro, tradicionalmente, entre os filhos das famílias influentes um era padre.

A Teologia da Libertação se manifesta como Comunidades Eclesiais de Base -as CEBs; como pastorais as mais diversas, com destaque para a CPT -Comissão Pastoral da Terra. Ou ainda, através da CONTAG, outra instituição de caráter nacional ou, ainda, simplesmente, criando Sindicatos de Trabalhadores Rurais, ou mesmo oposições sindicais, onde já havia sindicatos "pelegos".

Emerge, assim, um movimento importante que clama por direitos, introduzindo a lógica da cidadania no lugar da lógica do favor. A luta é desigual, posto que se dá sob um regime ditatorial e, embora, tenha contribuído decisivamente para a democratização do país, essa democratização se manteve nos limites da democracia formal. A luta pela Reforma Agrária, por exemplo, ficou empacada desde o primeiro governo civil após o fim da ditadura militar.

16- Como resposta a esse vigoroso movimento sindical rural, importantes conquistas sociais são inscritas na Constituição de 1988, como direitos sociais antes restritos aos trabalhadores urbanos. Muitos sindicatos passarão a se constituir em verdadeiros mediadores 
dessas conquistas, como as aposentadorias, por exemplo. Muitos, inclusive, viverão das contribuições de aposentados o que, por si só, põe em risco sua reprodução futura.

O próprio PAPP - Programa de Apoio ao Pequeno Produtor - trará enormes problemas ao sindicalismo rural que, diga-se de passagem, não conseguiu formular políticas públicas próprias, mesmo para aquelas políticas que eram, de certa forma, respostas a reivindicações do próprio movimento. Aqui é preciso sublinhar que esses programas são historicamente implementados menos para resolver os problemas a que seus recursos se destinam do que, muito mais, para esvaziar demandas socialmente postas e que tendem a expor os limites das pressões, no caso, vindas dos trabalhadores rurais organizados. A declaração do Ministro da Agricultura, ao liberar as verbas para um novo programa da mesma natureza do PAPP, o PRONAF, em que diz "agora eu quero ver os sem terra crescerem", mostra mais a preocupação em esvaziar a demanda do que em atendê-la.

Deste modo, contra os Sindicatos de Trabalhadores Rurais foram criadas em todo o país milhares de Associações de Pequenos Produtores para agenciar o PAPP, do mesmo modo que em 1964 foi baixado o Estatuto da Terra contra as Ligas Camponesas.

A partir do PAPP, os STRs ficaram com as bandeiras políticas e as Associações, criadas para terem acesso aos recursos do PAPP e, assim, como mediadoras dos interesses econômicos, ficaram ao sabor do jogo político clientelístico com fortes raízes no coronelismo da região. Deste modo, aquilo que seria a expressão de própria vitória política dos sindicatos, como os recursos do PAPP, acabaram sendo administradas e controladas pelos poderes tradicionais através das Associações. Os STRs não tinham nenhuma proposta técnicoeconômica para se contrapor aos pacotes que, com os próprios recursos do PAPP, subordinavam os agricultores.

Assinale-se, todavia, que o Norte de Minas passava, em particular, por um processo de tão profunda revolução na sua estrutura de relações socio-ecológicas, com mudanças tão significativas no próprio perfil demográfico de repartição da população rural-urbana, que a própria base social na qual se assentava o trabalho sindical, se transformava a uma velocidade que escapava à capacidade de organização dos "de baixo". Aqui o sentido do que invocamos como des-envolvimento assume toda a sua dimensão.

17- Os movimentos sociais organizados no Norte de Minas tiveram, assim, um momento extremamente importante nos anos oitenta, sobretudo, como parte da emergência da sociedade civil, numa região que, como vimos, o coronelismo, a cultura do favor, e não do direito, tem profundas raízes históricas. 
No entanto, é preciso que observemos, dadas as circunstâncias históricas, a hegemonia político-cultural daqueles segmentos que se recobrem com práticas religiosas no interior dos próprios movimentos sociais. Até porque essas correntes tendem a ter uma militância mais profissionalizada e, assim, condições de exercer uma hegemonia mais efetiva, do que uma militância não profissionalizada. A questão que se coloca hoje é se no contexto interno à própria Igreja, sobretudo à Católica, a componente democrática e popular, como aquela ligada à Teologia da Libertação, terá daqui por diante a mesma autonomia de ação ou apoio que veio tendo até recentemente. Tudo indica que, no contexto não mais de uma ditadura militar, onde a sociedade civil tem mais opções de buscar seus caminhos políticos, esse setor progressista perca espaço político no interior da própria Igreja, como já o demonstram o afastamento do Frei Leonardo Boff e mesmo a vitória de um Bispo conservador, D. Lucas Moreira Neves, nas últimas eleições na CNBB.

Pela importância que teve a ala progressista da Igreja na conformação de uma cultura política fundada na busca de direitos e não de favores, e pela hegemonia que ainda mantém no interior do movimento social rural no Norte de Minas, o destino do próprio movimento está, assim, muito ligado ao destino do setor progressista dentro da própria Igreja.

\section{O NORTE DE MINAS NO CONTEXTO DE UMA REORGANIZAÇÃO SOCIETÁRIA LOCAL/GLOBALIZADA}

18- O processo de reorganização porque vem passando o mundo desde os anos setenta, e que ganha contornos políticos mais nítidos, sobretudo após a queda do muro de Berlim, faz com que cada porção do planeta, cada lugar, cada região seja recontextualizada.

Um evento local pode ser funcionalizado por setores com poder de se articular numa outra escala e, assim, produzir efeitos mundiais. Articular o local ao global tem sido um desafio dos novos tempos. Novas questões como o Meio Ambiente, os Direitos Humanos e a de Gênero têm sido postas como valores à escala planetária e, portanto, se colocam como referência para qualquer ação política num mundo cada vez mais local/globalizado.

19- O Norte de Minas já vem sofrendo os impactos desse novo vetor globalizado que funcionaliza os lugares. Determinados recursos existentes na região foram selecionados, destacados, abstraídos da totalidade local/regional e funcionalizados por determinados vetores que operam não de modo solidário com o local/regional mas, ao contrário, ignorando essas totalidades que são os lugares. Seus cerrados ou suas chapadas, seus Gerais que, por exemplo, na totalidade local/regional eram terras comunais, são funcionalizados como carvão e integrados a uma escala nacional/internacional. 
Deste modo, o Norte de Minas foi interligado ao novo modelo industrial pós-anos setenta, com forte componente de empresas internacionais, com exportação de aço de boa qualidade, sem poluição adicional à escala global, pois não era queima de carvão fóssil. No entanto, foram profundas as conseqüências à escala local/regional. Os Geraizeiros e os Vazanteiros foram suas vítimas pela menor disponibilidade de terras, da menor disponibilidade de água, além da enorme perda da biodiversidade do cerrado e, assim, da sociodiversidade que, como vimos, se materializava num rico regime alimentar, hoje sob sério risco de não poder mais se reproduzir. Os Caatingueiros, por seu lado, estão sofrendo com a menor disponibilidade de água, na medida que na caatinga a disponibilidade de água é, naturalmente, menor que no cerrado. Os Gerais deixaram de ser gerais para virarem carvão para exportação sob a forma de aço e ligas metálicas de qualidade. O carvão do cerrado e dos maciços de eucalipto não só mudaram completamente o regime hídrico da região, isto é, o tempo em que a água fica disponível, como mudaram, também, a relação que a estrutura fundiária mantinha com os sistemas agrícolas que, por sua vez, conformavam um modo de vida.

A terra e a água já não são mais gerais, já não são mais livres, em virtude de uma determinada forma de integração subordinada à ordem nacional-internacional que, como vimos, contou com o apoio ativo dos "de cima" da própria região. A bio-socio-diversidade foi severamente agredida. Como são os valores de competitividade e produtividade que vêm comandando essa ordem que se quer centrada no mercado, a região se vê novamente ao sabor de forças de além. É o que se vê, por exemplo, com o carvão da ex-URSS que entra hoje no mercado a preços sem concorrentes, pondo em crise a própria produção de carvão na região do Norte de Minas. Ou, ainda, a importação de alho da Argentina, através do MERCOSUL, que não só trouxe a falência para cerca de 7.000 famílias de produtores familiares em Santa Catarina e no Rio Grande do Sul, como veio contribuir para o aumento da favela de Francisco Sá, município vizinho de Montes Claros que, também, produzia alho.

20- Para integrar-se a essa nova ordem, em que o mercado se apresenta como um (alguns querem que seja o único) regulador da alocação de recursos, uma mudança no sistema normativo se impõe. Seu nome é Reforma do Estado. Os diferentes setores da sociedade são, assim, chamados a se posicionar sobre essa questão.

A questão torna-se interessante no Norte de Minas na medida que o poder público dispõe de uma profunda capilaridade social, via coronelismo. Aliás, exatamente por ser essa a relação do Estado com a Sociedade, isto é, feita por mecanismos clientelísticos, via 
coronelismo, já indica que esses órgãos não eram públicos, no sentido de que estavam a serviço da sociedade como um todo e, sim, de interesses de algumas famílias.

A região contaria, por exemplo, "com mais de 30 órgãos públicos só para tratar com a área rural", nos afirmou um diretor-técnico de uma importante empresa pública, a EMATER.

Deste modo, é preciso estar atento para o modo como vai se dar, ou vem se dando, essa Reforma do Estado à escala local/regional. Reportamo-nos aqui à transformação no caráter da gestão das empresas públicas, como é o caso da EMATER ou do BNB. Elas passam no momento, como pudemos constatar, por um processo restruturação que vem sendo chamado de reengenharia ou de empresariamento.

Busca-se, por exemplo, no mercado a complementação do orçamento, como é o caso da EMATER. Em outro caso vê-se a contratação de funcionários por projeto, com contratos temporários e precários, ou pondo em prática a terceirização. O BNB, por exemplo, já não conta com nenhum engenheiro agrônomo atuando como tal em seus quadros funcionais. A EMATER irá disputar com as empresas de consultoria privadas o mercado de recursos públicos destinados, por exemplo, ao PRONAF. Quais as tendências de absorção pelo mercado de trabalho da população que se desenham na região, sobretudo quando se sabe que o empreguismo no setor público se colocou, particularmente nos últimos anos, como opção à desestruturação das relações sociais na área rural ? Afinal a migração para as cidades da região não foi absorvida pelos empregos prometidos pelos projetos industriais, muitos dos quais, sabemos, não passaram de fachadas para apropriação de recursos públicos. O que significa reengenharia, empresariamento ou terceirização numa moldura política marcada pelo coronelismo, de enraizada tradição de instrumentalização privada dos recursos públicos? O que significa disputar no mercado os recursos numa sociedade de extrema desigualdade social e os "de baixo" não têm como pagar por serviços? E mesmo as empresas de consultoria, que já começam a proliferar na região, a maior parte delas com nomes ecológicos e práticas nem tanto, cujos próprios técnicos foram formados ignorando completamente o saber-fazer das matrizes de racionalidade engendradas na história cultural dos 'de baixo', e sem nenhuma prática de tentar viabilizar o conhecimento que essas populações já têm dos ecossistemas e das suas tecnologias de enorme complexidade que se, de um lado, demandam aperfeiçoamentos, de outro, sem dúvida, exigem um saber de técnicos que tenham a sensibilidade, além da formação para compreendê-las, e que as contemplem e não que as ignorem?

Eis algumas das questões que se colocam como iminentes para as novas transformações que vêm se processando para o que, sem dúvida, a região já dispõe de um 
capital cultural importante para enfrentá-las, como o demonstram o Centro de Agricultura Alternativa $^{4}$, em Montes Claros, o Projeto Pé na Caminhada levado a cabo por professores e alunos da Escola Técnica Federal de Januária, que conta com o apoio do Bispo local e, o mais interessante, a incorporação da temática cultural-tecnológica como bandeira política pelos Sindicatos de Trabalhadores Rurais de Porteirinha e de Varzelândia, através dos princípios da agroecologia e da prioridade à agricultura familiar ${ }^{5}$.

\section{V- RAÍZES E ANTENAS}

21- No entanto, como assinalamos, um dos maiores desafios que se coloca hoje para aqueles que a partir do local/regional lutam por direitos e por justiça é o de se inserir, com suas singularidades, em outras escalas, como a nacional e a internacional. Enfim, agir e pensar local e globalmente e não como se dizia antes, agir localmente e pensar globalmente. Há que se fazer as duas coisas ao mesmo tempo, isto é, insistimos, agir e pensar local e globalmente.

A própria posição subordinada com que vem se dando a inserção do Brasil nessa ordem mundial, expõe a sociedade brasileira aos ditames que emanam dessa mesma escala global e à sua ordem de valores e significações.

Esse processo de reorganização societário que é, simultaneamente, local/regional/nacional/globalizado está longe de ser harmônico. Ao contrário, as contradições vicejam em diferentes localidades. Aliás, é ao nível dos lugares que as contradições se mostram mais agudamente. Não é desprovido de sentido que assim seja. É que a esse nível, do lugar, há uma totalidade solidária onde diferentes objetos e agentes sociais convivem ao mesmo tempo. O lugar se define pela con-vivência, pela co-existência dos objetos e das pessoas lado a lado, isto é, pelos entes co-lados, se me permite o leitor esse neologismo, para forçar a compreensão do argumento.

Há, assim e sempre, diferentes ritmos pulsando ao mesmo tempo nos diferentes lugares. Os vetores hegemônicos ligados ao grande capital financeiro e às firmas multinacionais selecionam as partes dos lugares que podem ser funcionalizadas de acordo com seus interesses. O lugar mesmo, enquanto tal, não lhes interessa. É uma nova versão de uma lógica que o Brasil já conhece e que levara Celso Furtado a falar de privatização dos lucros e socialização dos prejuízos.

\footnotetext{
${ }^{4}$ Atualmente denomiado de Centro de Agricultura Alternativa do Norte de Minas. Para maiores informações disponíveis em: <https://www.caa.org.br/>. Acesso em: abr. 2021.

${ }^{5}$ Para um panorama atual da questão agrária Norte Mineira e demais estudos envolvendo o campesinato e os povos e comunidades tradicionais indica-se: Costa (2017), Dayrell (2019) e Cepolini-Ferreira (2020).
} 
Há, assim, esse tempo rápido que se quer veloz e que hoje se integra através de redes telemáticas. A velocidade da comunicação da informação exige, por outro lado, novos objetos concretos, novas infra-estruturas, capazes de transportar as mercadorias tangíveis, palpáveis, os carvões, as frutas, o leite, o algodão o mais rapidamente possível.

A contradição se mostra, então, viva, podendo mesmo um lugar ser descartado por esses vetores hegemônicos em virtude de novas configurações, inclusive, normativas, como facilidades fiscais obtidas alhures. E, sabemos, como nessa crise fiscal porque passa o Estado, e não só no Brasil, as diferentes escalas administrativas - o município, o estado e o próprio Estado-Nação- têm empreendido uma verdadeira "guerra por emprego e renda", na feliz expressão do geógrafo David Harvey, quase sempre abdicando de impostos, fazendo isenções fiscais e, assim, só favorecendo a flexibilidade locacional dessas empresas que dispõem de flexibilidades locacionais e que, assim, abandonam hoje os lugares que, ontem, lhes favoreceram com isenções fiscais, da mesma forma que, amanhã, correrão em direção a lugares que lhes apresentem melhores "vantagens comparativas", entre elas, sem dúvida, as fiscais. No final das contas, um estado que, através dessa lógica concorrencial, só faz aprofundar a sua própria crise.

Enfim, cada vez cresce mais uma ideologia não-governamental, característica do neoliberalismo, indicando, com isso, uma crise de representação da sociedade civil. Vivemos a contradição de vermos cada vez mais se falar de poder local, quanto mais se afirma um poder global que dispõe de sofisticadas tecnologias para se capilarizar nos lugares, através de controle remoto, de sensoreamento remoto, isto é, de controle à distância (a telemática).

O interessante desses novos tempos é que as contradições quase sempre se mostram mais vivas quando emergem dos fundos, dos quintais, das periferias, isto é, ali onde as vertentes hegemônicas menos se fizeram presentes, mas que, também, não escapam desse mundo local/globalizado. É que aí predominam tempos mais lentos, outras matrizes de racionalidade, ainda não totalmente hegemonizadas. Foi por essa porta, por exemplo, que diferentes comunidades indígenas, Chiapas, por exemplo, ou mesmo os seringueiros, a partir de um lugar tão distante como Xapuri, adentraram a cena política local-globalizada. O mesmo pode ser dito do Movimento dos Sem Terra. Há, aqui, nessa dimensão local-globalizada o reconhecimento desses sujeitos sociais como cidadãos e, para isso, foi fundamental que se articulassem em uma outra escala, afirmando suas singularidades; que soubessem articular práticas tangíveis, que expressam seu poder de fato, suas raízes, ao mesmo tempo que se antenam. Por práticas tangíveis estou considerando os Empates, prática através da qual os seringueiros às dezenas ou centenas, mulheres e crianças incluídos, se interpõem para evitar a 
destruição de suas condições de sustentabilidade, no caso, a floresta; ou os Assentamentos dos Sem Terra, também garantindo suas condições de sustentabilidade, no caso a terra; ou as ações de ocupação de estradas e bloqueios dos indígenas de Chiapas. A partir dessas práticas tangíveis, com raízes, esses movimentos se inseriram nas redes e, assim, afirmavam seus lugares/suas práticas, ao mesmo tempo, que se antenavam, se globalizavam, sem tirar os pés do chão.

Registre-se que esses movimentos local/globalizados buscam a afirmação de direitos, da cidadania, que lhes é negada ou à escala local, ou à escala regional ou à escala nacional.

A globalização, como se vê, se mostra assim mais complexa, como um novo campo, ele, também, contraditório, de lutas e, portanto, de novas possibilidades. Esses movimentos deste modo, também, propugnam por um outro sistema normativo, também, por uma (outra) reforma do estado, não necessariamente a mesma que vem sendo (im)posta pelos vetores hegemônicos.

A reorganização societária local/globalizada que está em curso começa a demonstrar que está longe de ser unívoca, um pensèe unique. Ao contrário, comporta enormes possibilidades de encontros de sujeitos sociais os mais variados que se desconheciam, tanto à escala nacional como internacional, e que demandam outros sistemas normativos para se afirmarem.

Nessa agenda política local/globalizada os direitos humanos e a questão ambiental se tornam temas-brechas onde muitos movimentos sociais têm estabelecido articulações e, assim, superado barreiras que os isolava e, assim, subordinava-os. Divide et impera. Cada vez fica mais difícil se invocar a soberania nacional diante de questões como a tortura ou as queimadas.

22- No entanto, é preciso estar atento para uma dimensão extremamente importante, quase sempre negligenciada, desse processo de profunda reorganização societária que o mundo vem passando, e que diz respeito às novas formas de se apropriar dos espaços, de constituir novas marcas sobre os espaços, novas grafias, novas geo-grafias, enfim, novos territórios.

Um bom exemplo disso são as pressões para mudar o sistema de normas jurídicopolíticas como, por exemplo, a lei de patente, ou sobre o direito sobre a propriedade intelectual. Como ficam as velhas fronteiras geográficas, marcas na terra dos limites dos sistemas normativos, que demarcavam graus de autonomia, de soberania? Quem é que vai garantir o acesso, por exemplo, à biodiversidade? 
Como podemos observar o fim de determinadas marcas na terra, de determinadas geografias, o Estado-Nação, por exemplo, não elimina a questão da soberania. Afinal quem é o novo soberano? Em que escala, em que dimensão territorial ele irá decidir? Sobre que espaços? sobre que pessoas? sobre que recursos naturais? Quem os elege? Como vemos, o debate sobre a soberania, enquanto soberania nacional, acaba ofuscando quem vai decidir soberanamente. Talvez o debate sobre a questão da soberania, ideologizado enquanto a soberania nacional, venha prestando melhores serviços aos que negam essa mesma territorialidade, do que aos nacionalistas. São questões como essas, de quais são as novas grafias na terra, os novos territórios, que novos elos ligarão o local, ao regional, ao nacional, ao planetário, de suas retroalimentações, de suas autonomias, de soberanias, enquanto fonte e origem social do poder, de novos pactos territoriais, de novas comunidades (territoriais) de destino, mesmo que territórios que identifiquemos como campo de forças que nos é comum, ou como espaço comum de vivência de nossas de contradições, que está a exigir dos diferentes sujeitos sociais de cada lugar, de cada região um posicionamento para se inserir nessa ordem local/globalizada imprimindo suas marcas, suas identidades.

A questão da propriedade intelectual sobre o material genético, por exemplo, coloca em conflito diferentes matrizes de racionalidade, inclusive, de concepções de propriedade. Qualquer cientista natural, seja ele botânico, geógrafo, zoólogo e outros, sabe que muitas das suas pesquisas, muitas das suas teses, seriam impossíveis sem o conhecimento de caboclos, de pescadores, de camponeses, de diferentes povos indígenas. No entanto, raras são as teses que indicam que a propriedade intelectual derivada dessas informações pertence às comunidades que ali estão presentes (e ausentes) através das informações. Indicamos, por exemplo, a situação posta por novas concepções da natureza que ao recontextualizar a vida, no sentido biológico, atribuindo-lhe um valor a que antes não se dava, a partir da descoberta do DNA, da biologia molecular, da (Hipó)Tese de Gaia e de novos campos possíveis de mercantilização da vida através da biotecnologia. Neste caso a problemática ética emerge com toda a força e esse mesmo debate requer que nos apropriemos das informações postas pelo campo científico. Aqui, trata-se de apropriações de recursos (genéticos) cuja percepção chega mesmo a escapar da visão comum: ela exige microscópios de alta precisão e onde até mesmo problemas de escalas se colocam. Por outro lado, essa mesma re-significação da natureza abre espaços para que determinados segmentos sociais possam emergir à cena política e estabelecer um diálogo com a sociedade envolvente que, até aqui, os viam como atrasados/indolentes/preguiçosos, em suma, como algo a ser superado. Refiro-me aqui às chamadas "populações tradicionais" como as diferentes comunidades indígenas, camponesas e extrativistas (seringueiros, 
quebradeiras de coco babaçu e outras) que têm um acervo de conhecimentos forjado a partir de "outras matrizes de racionalidade". Ao mesmo tempo, essas lutas por afirmação de sentidos/práticas sociais têm deixado marcas na terra, grafado a terra, geografado, de modo inovador, tais como com as Reservas Extrativistas ou como com a Reserva Campesina de Biodiversidade, recentemente criada no México. Ao mesmo tempo têm-se colocado questões extremamente relevantes para o campo jurídico-político, na medida que essas populações tendo um conhecimento já reconhecido, inclusive, por diferentes instituições científicas, se colocam como portadoras de direito de propriedade intelectual sobre esses conhecimentos. Problemas de como efetivá-lo têm sido colocados, inclusive aqueles derivados de o direito que temos partir de uma matriz de racionalidade, o direito romano, fundada na propriedade privada. Isso porque para essas populações que, na sua maior parte não domina a escrita, todos têm livre acesso ao conhecimento ou, pelo menos, não têm interdições jurídico políticas para a ele aceder, sendo, assim um direito a ser partilhado em comum. E, diríamos mais, que essas antigas/atuais outras matrizes de racionalidade, que ganham direito à cidadania política em virtude de transformações, inclusive, na matriz do complexo industrial tecnológico que se vem operando, têm sido captadas estético-artisticamente por vários pesquisadores/artistas.

23- Há uma outra dimensão a que a revolução telemática está ligada que enseja e abre novas e outras perspectivas para as populações tradicionais. Ela diz respeito àquilo que Pierre Lèvy chamou de tecnologias da inteligência. É sabido que a informática, através do computador, torna possível que estabeleçamos uma lógica não-linear com o conhecimento. Ao contrário da escrita, por exemplo, que exige que obedeçamos à seqüência justaposta, linear, de cada letra, de cada palavra, de cada frase, da sequiência das frases, dos parágrafos, das páginas de um texto, através de um simples clique de um mouse podemos navegar de um assunto para outro, fazendo interconexões em rede tal e qual fazemos numa conversa de bar, quase sempre não-linear. O mesmo pode-se dizer dos saberes tradicionais, mais holísticos, não-lineares. Como as próprias teorias da comunicação nos esclarecem, a informação é diferente do dado. A informação pressupõe que o dado foi apropriado por uma matriz cultural que lhe dá sentido, que lhe dá significação. Sendo assim, por exemplo, não basta que exista uma espécie botânica. É necessário que ela tenha ganho a dimensão de informação que, por sua vez, pressupõe uma cultura. Assim, junto com a biodiversidade que, muitos vêm destacando, necessariamente também ganha dimensão política a diversidade cultural. A tradição ganha a dimensão de suporte de modernidade. A cultura é um verdadeiro software e, como tal, também suscetível de proteção tanto quanto a IBM procura fazer dos seus. Como se vê a complexidade não é somente um novo paradigma. 
E, mais, sabemos que esses conhecimentos nunca pertencem a um ou outro membro dessas populações, mas a todos, o que, coloca, como vimos, no mínimo, um problema para o nosso direito que tem como princípio uma normatização com base na propriedade privada, individual e, cada vez menos pensa, ou mal-pensa quando pensa, o direito patrimonial, o bem comum, o bem coletivo.

O Norte de Minas, por exemplo, dispõe para isso de um enorme capital de recursos: uma enorme bio-socio-diversidade que se expressa em ecossistemas como a Caatinga e o Cerrado; em matrizes de racionalidade variadas como os Geraizeiros, os Caatingueiros e os Vazanteiros que nos legaram um regime alimentar diversificado, um vasto conhecimento de plantas medicinais, além de um saber acerca das dinâmicas ecológicas que só uma convivência continuada no tempo lhes permitiu elaborar. Tudo isso é, rigorosamente falando, a riqueza do Norte de Minas.

Numa época em que o conhecimento da biodiversidade torna-se um suporte importante para um setor de ponta do desenvolvimento tecnológico, o da biotecnologia, o conhecimento desenvolvido por essas matrizes de racionalidade Caatingueira, Vazanteira e Geraizeira, até aqui tidas como tradicionais e, por isso, desqualificadas como interlocutores, adquirem uma qualidade positiva. São trunfos para um diálogo com o mundo. Mais do que nunca sua cultura, sua singularidade que, na verdade, faz do Norte de Minas ser o que ele é, é a carta que deve ser sacada do baralho para dialogar com o mundo, isto é, com as Minas Gerais, com o Brasil e esse mundo cuja reorganização societária em curso, se não vislumbrarmos o que somos, a singularidade que temos, a partir riqueza de nossas matrizes de racionalidade construídas a partir do lugar/região que vivemos e da abertura que temos, necessariamente transformará tudo numa Disney ou num Mcdonald.

Há, assim, um processo de globalização que só vê os lugares para nele tentar funcionalizar, destacar, isolar, aquilo que interessa a um tempo, o do capital, que tende para ser retilíneo, uniforme e linear que é o tempo da velocidade do global; mas há uma outra perspectiva que se coloca como um global que seja tão rico como são as riquezas plurais dos diferentes lugares, com seus diferentes tempos, com suas diferentes matrizes de racionalidade.

Um axioma daí deriva: a velocidade não nos permite captar as paisagens, captar as diferenças dos lugares. Para isso é preciso um outro tempo, outros tempos.

Tudo isso está a exigir movimentos sociais que saibam articular raízes e antenas; que saibam construir suas identidades incorporando novos valores, novas bandeiras. O potencial político-cultural do Norte de Minas é enorme, a começar com o convite a todos os mineiros para refletir sobre o que será das Minas Gerais quando as águas já não minam no Norte de 
Minas (só no Norte de Minas?), nem tampouco os Gerais são mais gerais, posto que foram privatizados...

\section{REFERÊNCIAS}

CEPOLINI-FERREIRA, Gustavo H. (Org.). Atlas da questão agrária Norte Mineira. São Paulo: Entremares, 2020.

COSTA, Sandra. H. G. 'Recantilados', entre o direito e o rentismo: grilagem judicial e a formação da propriedade privada da terra no norte de Minas Gerais. São Paulo: Programa de Pós-Graduação em Geografia Humana - FFLCH. DEGEO/FFLCH/USP, 2017.

DAYRELL, Carlos Alberto. De nativos e de caboclos: reconfiguração do poder de representação de comunidades que lutam pelo lugar. Tese de Doutorado - Desemvolvimento Social. PPGDS/UNIMONTES. Montes Claros: PPGDS, 2019.

PORTO-GONÇALVES, Carlos Walter. As Minas e os Gerais: breve ensaio sobre desenvolvimento e sustentabilidade a partir da Geografia do Norte de Minas. In: VII Simpósio Brasileiro de Geografia Física Aplicada e I Fórum Latino-Americano de Geografia Física Aplicada, 1997.

PORTO-GONÇALVES, Carlos Walter. As Minas e os Gerais - breve ensaio sobre desenvolvimento e sustentabilidade a partir da Geografia do Norte de Minas. In: LUZ, C. e DAYRELL, C. (Orgs.). Cerrado e Desenvolvimento: tradição e atualidade. Montes Claros: Max Gráfica e Editora, 2000.

Artigo recebido em: 07 de abril de 2021.

Artigo aceito em: 13 de abril de 2021.

Artigo publicado em: 01 de maio de 2021. 